Check for updates

Cite this: Chem. Commun., 2021, 57,7709

Received 8th June 2021

Accepted 17th June 2021

DOI: $10.1039 / \mathrm{d} 1 \mathrm{cc} 03026 \mathrm{~d}$

rsc.li/chemcomm

\section{Design and enantioselective synthesis of 3-( $\alpha$-acrylic acid) benzoxaboroles to combat carbapenemase resistance $\dagger$}

\author{
You-Cai Xiao, (DD ${ }^{a}$ Xiao-Pan Chen, ${ }^{a}$ Ji Deng, ${ }^{a}$ Yu-Hang Yan, ${ }^{a}$ Kai-Rong Zhu, ${ }^{a}$ \\ Gen Li, ${ }^{a}$ Jun-Lin Yu, Jürgen Brem, (D ${ }^{b}$ Fener Chen, ${ }^{a}$ Christopher J. Schofield (DD *b \\ and Guo-Bo Li (D) *a
}

\begin{abstract}
Chiral 3-substituted benzoxaboroles were designed as carbapenemase inhibitors and efficiently synthesised via asymmetric Morita-Baylis-Hillman reaction. Some of the benzoxaboroles were potent inhibitors of clinically relevant carbapenemases and restored the activity of meropenem in bacteria harbouring these enzymes. Crystallographic analyses validate the proposed mechanism of binding to carbapenemases, i.e. in a manner relating to their antibiotic substrates. The results illustrate how combining a structure-based design approach with asymmetric catalysis can efficiently lead to potent $\beta$-lactamase inhibitors and provide a starting point to develop drugs combatting carbapenemases.
\end{abstract}

The benzoxaborole ring system has emerged as a useful drug scaffold, due to its intrinsic reactivity, metabolic stability and low toxicity. ${ }^{1}$ Benzoxaborole derivatives have been developed to treat infectious, inflammatory and neoplastic diseases; ${ }^{2}$ Tavaborole and Crisaborole are approved for treatment of onychomicosis and mild-to-moderate atopic dermatis, respectively and other benzoxaboroles are in development (Fig. 1a). ${ }^{3}$ However, most benzoxaborole containing drugs/drug candidates have achiral substituents, hampering the development of selectivity. The development of efficient new methods for the asymmetric construction of chiral benzoxaboroles, including with C3 substituents is a current challenge in the development of boron containing drugs.

Procedures have been recently described for synthesis of C3-substituted benzoxaboroles via reaction of nucleophiles with 2-formyl aryl boronic acid. ${ }^{1 a}$ Most, however, suffer from low yields and limited substrate scope. ${ }^{1 b}$ Indeed, there has been

\footnotetext{
${ }^{a}$ Key Laboratory of Drug-Targeting and Drug Delivery System of the Ministry of Education and Sichuan Research Center for Drug Precision Industrial Technology, West China School of Pharmacy, Sichuan University, Chengdu 610041, China. E-mail: liguobo@scu.edu.cn

${ }^{b}$ Department of Chemistry and the Ineos Oxford Institute for Antimicrobial Research, University of Oxford, 12 Mansfield Road, Oxford, OX1 3TA, UK. E-mail: christopher.schofield@chem.ox.ac.uk

$\dagger$ Electronic supplementary information (ESI) available: Spectroscopy details have been deposited. See DOI: 10.1039/d1cc03026d
}

little progress towards the asymmetric synthesis of 3substituted benzoxaboroles suitable for biological testing, with only a Wittig/oxa-Michael reaction cascade from 2-formyl aryl boronic acid having been reported. ${ }^{4}$

A major mechanism of carbapenem resistance involves production of carbapenemases, i.e. evolved $\beta$-lactamases that inactivate carbapenem antibiotics, which can be divided into two categories: serine-carbapenemases (e.g. Ambler class A KPC-2 and class D OXA48 types) and metallo-carbapenemases (e.g. NDM and VIM types). ${ }^{5}$ With the aim of helping enable agents to overcome carbapenem resistance in Gram-negative pathogens, ${ }^{6}$ we analysed carbapenemsubstrate derived complexes and identified benzoxaboroles with a C3 acrylic acid group as potential inhibitors (Fig. 1b). Here we

(a)

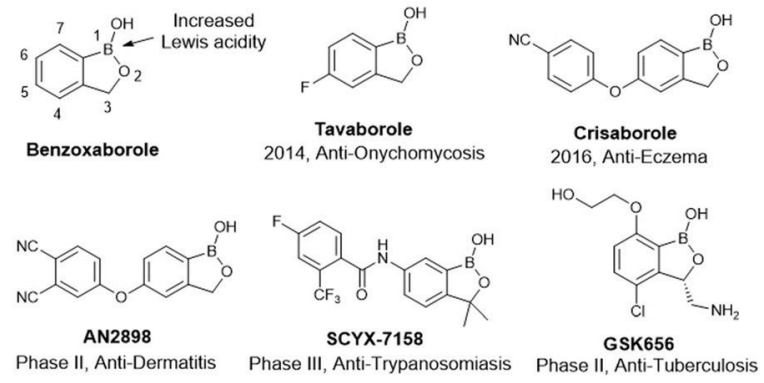

(b)

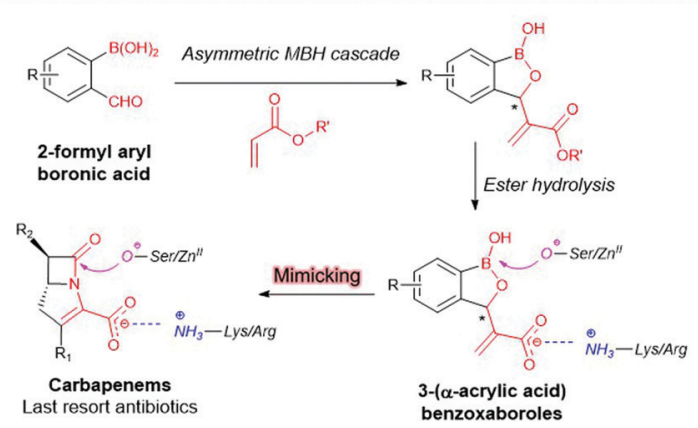

Fig. 1 Design of 3 -substitued benzoxaboroles as $\beta$-lactamase Inhibitors. 
report use of an asymmetric Morita-Baylis-Hillman (MBH) cascade reaction $^{7}$ to construct the desired chiral C3-substituted benzoxaboroles. Some of the compounds manifested inhibition of clinically relevant carbapenemases, with the proposed mode of action being validated by crystallography and potentiation of carbapenem activity in cells.

Initially, we utilized 2-formyl-phenylboronic acids as the electrophiles and hexafluoroisopropyl acrylate (HFIPA) as the activated alkene in model reactions. We envisaged challenges relating to the limited substrate scope of the $\mathrm{MBH}$ reaction, the desire for asymmetric induction, ${ }^{7 c}$ and the presence of a boronic acid group at the benzaldehyde ortho-position. After optimization of the model reaction, we identified reaction conditions using cinchona alkaloid derived chiral tertiary amines $\mathbf{C 6}$ and $\mathbf{C 7}$ as catalysts (see $\mathrm{ESI} \dagger$ for optimization details).

We explored the scope of the asymmetric reaction with various substituted 2-formylphenylboronic acids using C6 (Table 1). The products 3 were hydrolyzed to the corresponding carboxylic acids 4 for biological evaluation. The chiral $\mathrm{MBH}$ adducts made using $\mathbf{C 6}$ were assigned the $R$-configuration, based on X-ray analysis of a single crystal of $4 \mathbf{a}^{8}$

The asymmetric $\mathrm{MBH}$ reaction with aromatic aldehydes bearing electron-donating groups is reported to be challenging,

Table 1 Substrate scope with small substituents on the phenyl ring of 2formylphenylboronic acids ${ }^{a}$

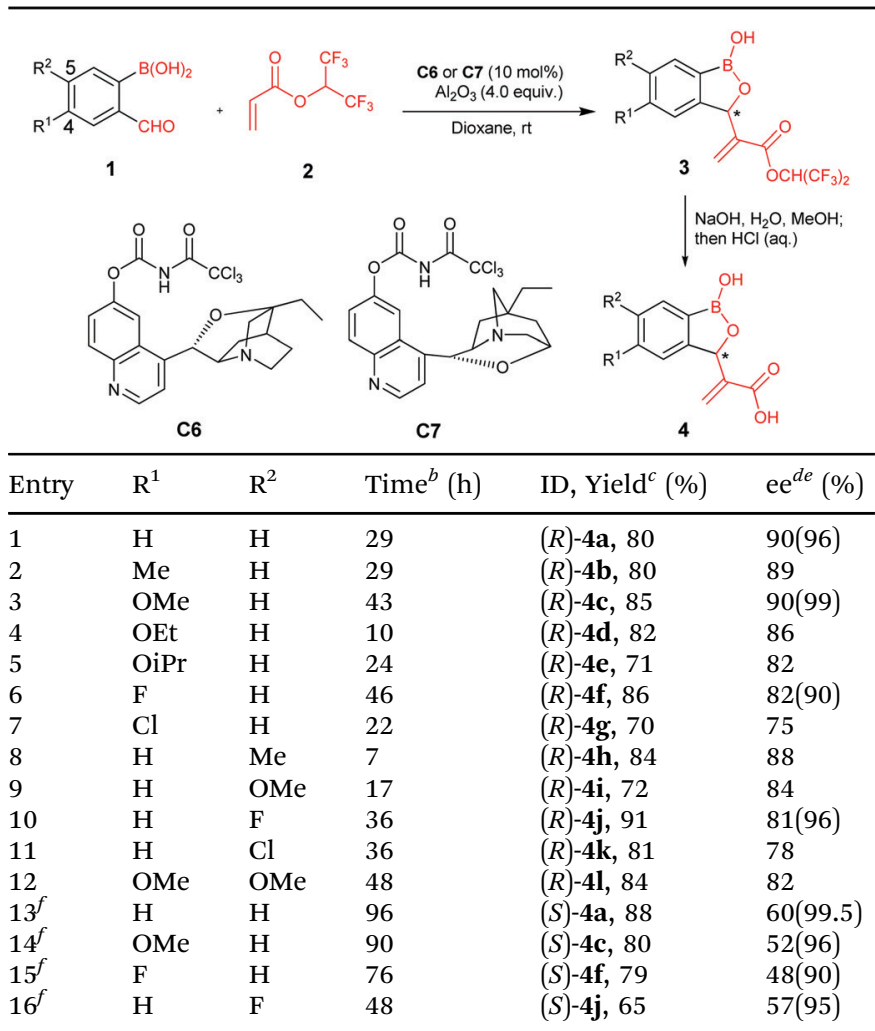

${ }^{a}$ Standard reaction conditions: $\mathbf{1}(0.1 \mathrm{mmol}), 2(0.5 \mathrm{mmol}), \mathbf{C 6}$ or $\mathbf{C 7}$ $(0.01 \mathrm{mmol}), \mathrm{Al}_{2} \mathrm{O}_{3}(0.4 \mathrm{mmol}), 1,4$-dioxane $(4.0 \mathrm{~mL})$, r.t. ${ }^{b}$ Reaction time for the first step. ${ }^{c}$ Isolated yields over two steps. ${ }^{d}$ ee's were determined by chiral HPLC. ${ }^{e}$ ee after recrystallization from ethyl acetate. ${ }^{f}$ Reaction at $0{ }^{\circ} \mathrm{C}$. owing to their low reactivity. ${ }^{7}$ However, electron-donating groups, e.g. methyl and alkoxy groups at $\mathrm{C} 4$ of the 2-formylphenylboronic ring are well tolerated in our conditions (Table 1, entries 1-5); it is possible that the aldehyde is activated by an intramolecular hydrogen bond between its carbonyl oxygen and the boronic acid, so promoting $\mathrm{MBH}$ reaction. ${ }^{9}$ By contrast, electron-withdrawing substituents at the same position in the phenyl ring delivered relatively low enantioselectivities (entries 6 and 7). Similarly, substituents at C5 of the 2-formylphenylboronic ring were amenable to reaction regardless of the electronic properties of the tested substituents (entries 8-12). However, substituents at either C3- or C6- of the 2-formylphenylboronic ring were not amenable to reaction, with only traces of the desired products being observed, revealing a limitation of the methodology. We applied catalyst $\mathbf{C 7}$ for the asymmetric $\mathrm{MBH}$ synthesis of $(S)$-enantiomers; the desired products were observed in good yield, albeit with moderate ee (entries 13-16); pleasingly, excellent ee's were obtained after recrystallization.

We next examined the reaction scope with larger substituents, e.g. aryloxy and benzyloxy groups, at $\mathrm{C} 4$ and C5- of 2-formylphenylboronic acids, since structural analyses suggested these derivatives are of interest as $\beta$-lactamase inhibitors (representatives are given in Scheme 1). ${ }^{10}$ Aryloxy substituents, ( $p$-tolyloxy, $m$-tolyloxy, $p$-trifluoromethyl-phenoxy) at $\mathrm{C} 4$ of 2-formylphenylboronic acids gave products (4m-4o) in high yields and good enantioselectivities. A benzyloxy group at $\mathrm{C} 4$ was also amenable to reaction, affording $\mathbf{4 p}$ in $81 \%$ yield and $87 \%$ ee. By contrast, aryloxyl- and benzyloxy substituents at C5 of 2-formylphenylboronic acids gave relatively lower ee's compared to the $\mathrm{C} 4$ derivatives $(\mathbf{4 q}-\mathbf{4 t})$. Density functional

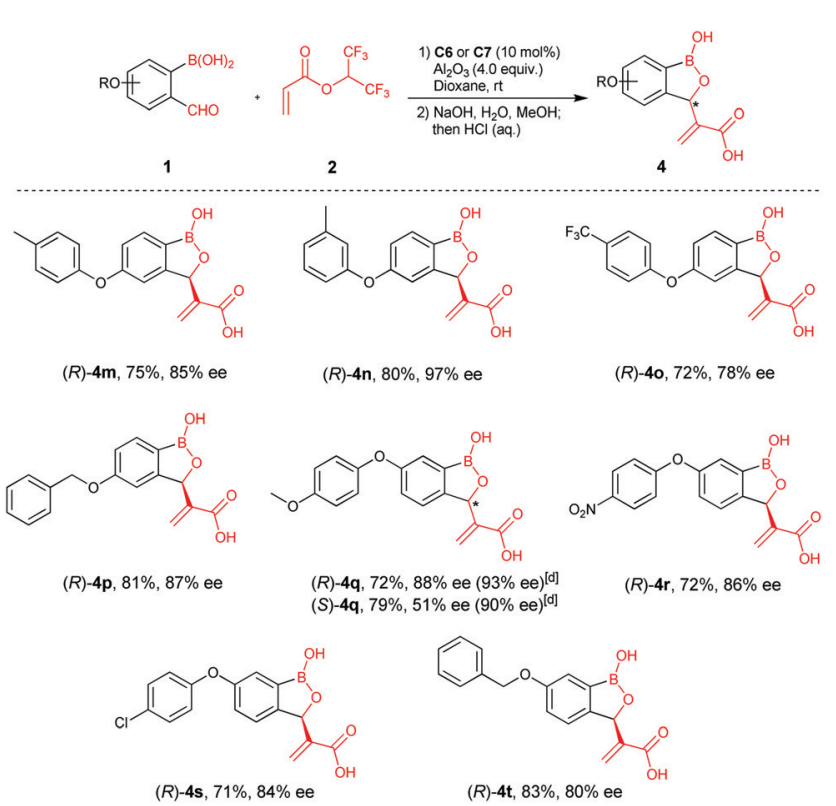

Scheme 1 Scope of C3 substituted benzoxaborole synthesis employing aryloxy and benzyloxy substituted 2-formylphenylboronic acids. ${ }^{a, b, c}$ anless otherwise stated, reactions were performed with $1(0.1 \mathrm{mmol}), 2$ $(0.5 \mathrm{mmol}), \mathbf{C} 6$ or $\mathbf{C 7}(0.01 \mathrm{mmol}), \mathrm{Al}_{2} \mathrm{O}_{3}(0.4 \mathrm{mmol}), 1,4$-dioxane $(4.0 \mathrm{~mL})$, r.t. $12-48 \mathrm{~h}$. ${ }^{b}$ Isolated yields over two steps. ${ }^{c}$ ee's determined by chiral HPLC. ${ }^{d}$ ee after recrystallization. 
theory (DFT) calculations inform on the mechanism of reaction and rationalise its stereoselectivity (see E. 1 Chemistry in ESI $\dagger$ ).

We then tested the activity of the benzoxaborole derivatives against purified recombinant forms of 7 types of clinically relevant $\beta$-lactamases, i.e. class A SBL KPC-2, class C SBL AmpC, class D SBL OXA-48, class B1 MBLs NDM-1, IMP-1, VIM-1, and VIM-2; the SBL inhibitor avibactam was used as a positive control (Table 2 and Table S1, ESI $\dagger$ ).

The results (Table 2) show both enantiomers of some of the chiral benzoxaborole derivatives manifest moderate, or potent, inhibition of the carbapenemase KPC-2, demonstrating their potential for inhibition of clinically relevant SBLs. In all cases, the $(S)$-configured compounds (4a, $\mathbf{4 c}, \mathbf{4 f}, \mathbf{4 j}, \mathbf{4 q})$ were more potent than the corresponding $(R)$-enantiomers, illustrating how chirality can confer selectivity in boron based SBL inhibitors. This selectivity was mostly, but not exclusively observed for the other $\beta$-lactamases, substantial inhibition of which was more sporadic than for KPC-2 (Table 2). The KPC-2 stereoselectivity for the benzoxaborole derivatives is interesting since the penicillin substrates of some of the $\beta$-lactamases have a $(2 S)$ C-3 carbon adjacent to their C-2 carboxylate. The difference in results for the $(R)$ - and $(S)$-benzoxaboroles may reflect different distances between their carboxylate and electrophilic boron; the analogous carboxylate to $\beta$-lactam distance is proposed to be important with respect to antibacterial activity. ${ }^{11}$

Overall, these results reveal that when combined with an appropriate C- 5 or C- 6 substituent, the C-3 acrylate substituted benzoxaborole derivatives are potent KPC-2 inhibitors. They were in general much less potent inhibitors for the other tested SBLs/MBLs, but in some cases potent inhibition was observed, suggesting that with optimisation the scaffold could be developed into potent broad spectrum $\beta$-lactamase inhibitors.

The abilities of selected Inhibitors to potentiate the antibacterial activity of meropenem (MEM), a clinically important carbapenem, was then investigated for AmpC, TEM-1, or KPC-2 producing clinically derived strains, including Klebsiella Pneumoniae C692, Escherichia coli BAA-2340, and Escherichia coli 11119 (for details, see ESI $\dagger$ ). None of these isolates were

Table 2 Comparison of the inhibitory activities $\left(\mathrm{IC}_{50}, \mu \mathrm{M}\right)$ of $(R)$ - and (S)configuration of selected benzoxaboroles ${ }^{a}$

\begin{tabular}{|c|c|c|c|c|c|c|c|}
\hline Cpd ID & $\begin{array}{l}\text { Class } \\
\text { A KPC-2 }\end{array}$ & $\begin{array}{l}\text { Class } \\
\text { C } \\
\text { AmpC }\end{array}$ & $\begin{array}{l}\text { Class D } \\
\text { OXA- } 48\end{array}$ & $\begin{array}{l}\text { Class } \\
\text { B1 } \\
\text { NDM-1 }\end{array}$ & $\begin{array}{l}\text { Class } \\
\text { B1 IMP-1 }\end{array}$ & $\begin{array}{l}\text { Class } \\
\text { B1 } \\
\text { VIM-1 }\end{array}$ & $\begin{array}{l}\text { Class } \\
\text { B1 } \\
\text { VIM-2 }\end{array}$ \\
\hline$(R)-\mathbf{4 a}$ & 3.08 & 134.10 & 15.84 & 549.80 & $>600$ & $>600$ & 225.40 \\
\hline$(S)-\mathbf{4 a}$ & 0.48 & 185.7 & 14.06 & $>600$ & 142.5 & 308.6 & 12.05 \\
\hline$(R)-\mathbf{4 c}$ & 7.62 & 178.20 & 42.52 & $>600$ & $>600$ & $>600$ & 232.60 \\
\hline$(S)-4 c$ & 0.54 & 74.14 & 34.15 & 169.7 & $>600$ & 466.3 & 22.40 \\
\hline$(R)-\mathbf{4 f}$ & 3.87 & 140.90 & 10.13 & $>600$ & 65.65 & 513.8 & 82.80 \\
\hline$(S)-\mathbf{4 f}$ & 0.34 & 149.8 & 14.68 & 325.3 & 46.5 & $>600$ & 120.5 \\
\hline$(R)-\mathbf{4} \mathbf{j}$ & 0.97 & 140.50 & 5.97 & $>600$ & $>600$ & $>600$ & 55.87 \\
\hline$(S)-\mathbf{4 j}$ & 0.49 & 108.7 & 12.03 & 719.1 & 142.5 & 308.6 & 105.7 \\
\hline$(R)-\mathbf{4 q}$ & 0.07 & 18.38 & 0.43 & 260.00 & 497.36 & 388.3 & 57.37 \\
\hline$(S)-\mathbf{4 q}$ & 0.01 & 22.52 & 0.74 & 34.06 & $>600$ & $>600$ & 58.49 \\
\hline Avibactam & 0.004 & 0.24 & 0.17 & $>600$ & 425 & $>600$ & 19.08 \\
\hline
\end{tabular}

${ }^{a}$ All tested compounds were recrystallised. IC $_{50}$ curves are shown in ESI Fig. S1.
Table 3 In vitro cell-based screening of $\mathbf{4 a}, \mathbf{4 c}$, and $\mathbf{4} \mathbf{q}^{a}$

\begin{tabular}{|c|c|c|c|c|}
\hline \multirow[b]{2}{*}{ Compound } & \multirow[b]{2}{*}{$\begin{array}{l}\text { Conc. } \\
(\mu \mathrm{M})\end{array}$} & \multicolumn{3}{|c|}{$\operatorname{MEM}\left(\mu \mathrm{g} \mathrm{ml}{ }^{-1}\right)$ in presence or absence of inhibitor } \\
\hline & & $\begin{array}{l}\text { K. pneumoniae } \\
\text { C692 (blaAmpC, } \\
\text { blaTEM-1) }\end{array}$ & $\begin{array}{l}\text { E. coli BAA-2340 } \\
\text { (blaKPC-2) }\end{array}$ & $\begin{array}{l}\text { E. coli } 11119 \\
\text { (blaKPC-2) }\end{array}$ \\
\hline - & - & $>128$ & 16 & 64 \\
\hline \multirow[t]{2}{*}{$(R)-\mathbf{4 a}$} & 100 & 16 & 0.25 & 0.5 \\
\hline & 10 & 128 & 0.5 & 4 \\
\hline \multirow[t]{2}{*}{$(S)-\mathbf{4 a}$} & 100 & 8 & 0.25 & 0.5 \\
\hline & 10 & 64 & 0.5 & 2 \\
\hline \multirow[t]{2}{*}{$(R)-4 \mathrm{c}$} & 100 & 128 & 0.5 & 2 \\
\hline & 10 & $>128$ & 2 & 16 \\
\hline \multirow[t]{2}{*}{$(S)-\mathbf{4 c}$} & 100 & 32 & 0.25 & 1 \\
\hline & 10 & 128 & 4 & 4 \\
\hline \multirow[t]{2}{*}{$(R)-\mathbf{4 q}$} & 100 & $>128$ & 1 & 2 \\
\hline & 10 & $>128$ & 2 & 16 \\
\hline \multirow[t]{2}{*}{$(S)-\mathbf{4 q}$} & 100 & 64 & 0.25 & 2 \\
\hline & 10 & $>128$ & 1 & 16 \\
\hline
\end{tabular}

${ }^{a}$ Clinically isolated strains producing KPC-2, AmpC, and/or TEM-1.

susceptible to MEM alone (MIC $\geq 16 \mu \mathrm{g} \mathrm{ml}^{-1}$ ); for the control strain ATCC25922, the MEM MIC is $0.06 \mu \mathrm{g} \mathrm{ml}^{-1}$.

Addition of $\mathbf{4 a}, \mathbf{4 c}$ or $\mathbf{4 q}$ at $100 \mu \mathrm{M}$ substantially reduced the MEM MICs, i.e. by 16-128 fold for the KPC-2 producing E. coli strains; notably, the presence of $10 \mu \mathrm{M}(R)-\mathbf{4 a}$ and $(S)-\mathbf{4 a}$ decreased the MEM MICs to below $2 \mu \mathrm{g} \mathrm{ml} \mathrm{ml}^{-1}$ for $E$. coli BAA-2340 and E. coli 11119 (Table 3). Consistent with the biochemical results, reduced (but still clear) activity was observed for AmpC and TEM-1 (both class A SBLs) producing $K$. pneumoniae C692, i.e. the addition of $100 \mu \mathrm{M}(S)-4 a$ resulted in a 16-fold decrease in the MEM MICs. Overall, consistent with the biochemical results, the $(S)$-compounds show better cellular activity than the corresponding $(R)$-enantiomers, illustrating the importance of stereochemistry. Interestingly, although $\mathbf{4 q}$ was a better inhibitor than 4 a versus against the isolated $\beta$-lactmases (Table 2), it was less active in restoring MEM activity in cells (Table 3 ), possibly reflecting different permeation or efflux properties.

To investigate the structural basis of inhibition by the chiral benzoxaboroles, we obtained KPC-2:(S)-4a and OXA-48:(R)-4a complex structures by co-crystallisation (Table S2, ESI $\dagger$ ). The KPC-2: $(S)$-4a structure reveals a covalent bond between boron and Ser70, with hydrogen bonds between the inhibitor and $\beta 3$ Thr237, $\alpha 8$ Ser130, $\beta 3$ Thr235, and $\beta 3$ Thr237 (Fig. 2a and Fig. S4, ESI $\dagger$ ). The OXA-48:(R)-4a structure similarly reveals a tetrahedral boron with hydrogen bonds between the inhibitor $\alpha 3$ Ser70, $\beta 5$ Tyr211, $\alpha 5$ Ser118, and $\alpha 10$ Arg250; Lys73 of OXA48 was refined in its catalytically active carbamylated form (Fig. 2b and Fig. S5, ESI $\dagger$ ). Superimposition of structures of KPC-2:(S)-4a with KPC-2:reacted imipenem (PDB: 6XJ8), ${ }^{12}$ and OXA-48:(R)-4a with OXA-48:reacted meropenem (PDB: 6P98) ${ }^{13}$ reveals that $(S)$-4a and $(R)-\mathbf{4 a}$ have binding modes closely related with those of ring-opened products of carbapenems (for more details, see Fig. S7-S9, ESI $\dagger$ ). Based on these structures and computational results, it is proposed that the C-6 4-methoxyphenoxyl group of $(S)$-4q, which occupies a hydrophobic subpocket adjacent to OXA-48 active site, forms an additional hydrogen bond with Asn170 of KPC-2 (Fig. S6, ESI $\dagger$ ). 
(a)

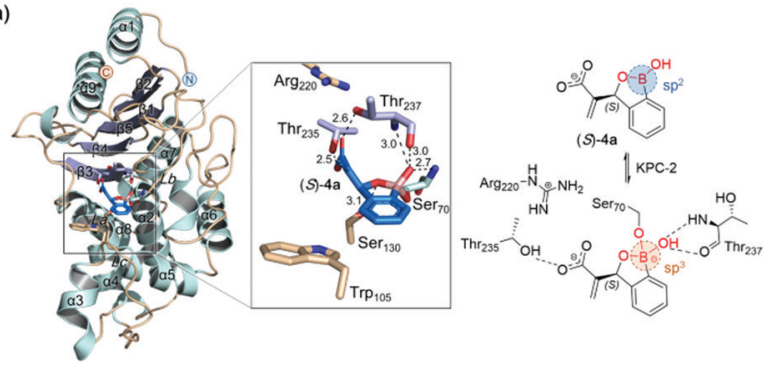

(b)

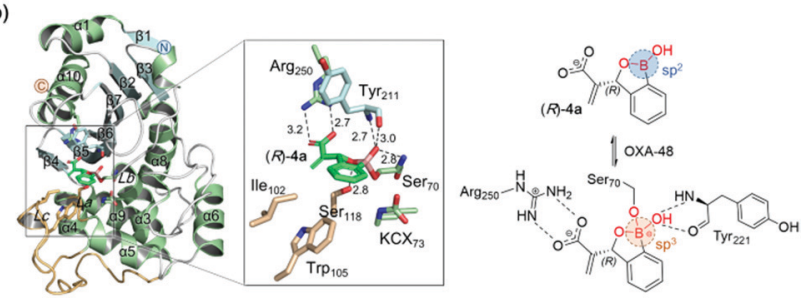

Fig. 2 Crystallographic analyses of the KPC-2:(S)-4a (PDB: 7E9A) and OXA-48:(R)-4a (PDB: 7DML) complexes.

This putative interaction may explain why $\mathbf{4 q}$ is more potent than $\mathbf{4 a}$ and suggests that further optimization of substituents particularly at C-6 should improve the potency of the series for carbapenemase inhibition.

In summary, an enantioselective $\mathrm{MBH}$ cascade reaction, employing a bifunctional tertiary amine-carbamate catalyst, was developed for efficient synthesis of 3-substituted benzoxaboroles. The reaction enabled synthesis of C3 acrylate substituted benzoxaboroles in high yield and enantiomeric excess. Screening against clinically relevant SBLs and MBLs, revealed that some of the benzoxaborole derivatives are potent inhibitors of SBLS/MBLs. Crystallographic analyses revealed that active site of $(S)-4 a$ to KPC2 and of $(R)-4 a$ to OXA-48 involves reaction with the nucleophilic serine. $(R)-\mathbf{4 a}$ and $(S)$-4a potentiate carbapenem activity in cells. The results thus provide an excellent starting point for optimisation to develop selective benzoxaborole derivatives to combat carbapenemase resistance.

The authors thank the staff of BL19U1 beamline of the National Center for Protein Science Shanghai at Shanghai Synchrotron Radiation Facility for assistance during data collection. The authors are grateful to the National Natural Science Foundation (Grant numbers: 81874291, 21907072, and 82073698). CJS thanks the Medical Research Council and the Wellcome Trust for funding. This work was funded in whole, or in part, by the Wellcome Trust (Grant number 106244/Z/14/Z).

\section{Conflicts of interest}

There are no conflicts to declare.

\section{Notes and references}

1 For selected reviews, see: (a) A. Adamczyk-Woźniak, K. M. Borys and A. Sporzyński, Chem. Rev., 2015, 115, 5224; (b) G. R. Mereddy, A. Chakradhar, R. M. Rutkoski and S. C. Jonnalagadda, J. Organomet. Chem., 2018, 865, 12; (c) Z. J. Leśnikowski, Expert Opin. Drug Discovery, 2016, 11, 569; (d) C. T. Liu, J. W. Tomsho and S. J. Benkovic, Bioorg. Med. Chem., 2014, 22, 4462.

2 (a) A. Nocentini, C. T. Supuran and J. Y. Winum, Expert Opin. Ther. Pat., 2018, 28, 493; (b) J. Zhang, J. Zhang, G. Hao, W. Xin, F. Yang, M. Zhu and H. Zhou, J. Med. Chem., 2019, 62, 6765; (c) Y.-H. Yan, Z.-F. Li, X.-L. Ning, J. Deng, J.-L. Yu, Y. Luo, Z. Wang, G. Li, G.-B. Li and Y.-C. Xiao, Bioorg. Med. Chem. Lett., 2021, 41, 127956.

3 J. Plescia and N. Moitessier, Eur. J. Med. Chem., 2020, 195, 112270.

4 G. Hazra, S. Maity, S. Bhowmick and P. Ghorai, Chem. Sci., 2017, 8, 3026.

5 (a) A. M. King, S. A. Reid-Yu, W. Wang, D. T. King, G. De Pascale, N. C. Strynadka, T. R. Walsh, B. K. Coombes and G. D. Wright, Nature, 2014, 510, 503; (b) A. M. Queenan and K. Bush, Clin. Microbiol. Rev., 2007, 20, 440; (c) N. J. Torelli, A. Akhtar, K. DeFrees, P. Jaishankar, O. A. Pemberton, X. Zhang, C. Johnson, A. R. Renslo and Y. Chen, ACS Infect. Dis., 2019, 5, 1013; (d) K. Bush and G. A. Jacoby, Antimicrob. Agents Chemother., 2010, 54, 969.

6 (a) K. Bush and P. A. Bradford, Nat. Rev. Microbiol., 2019, 17, 295; (b) A. Krajnc, P. A. Lang, T. D. Panduwawala, J. Brem and C. J. Schofield, Curr. Opin. Chem. Biol., 2019, 50, 101; (c) J. Brem, S. S. van Berkel, W. Aik, A. M. Rydzik, M. B. Avison, I. Pettinati, K.-D. Umland, A. Kawamura, J. Spencer, T. D. Claridge, M. A. McDonough and C. J. Schofield, Nat. Chem., 2014, 6, 1084.

7 For selected reviews and examples, see: (a) Y. Wei and M. Shi, Chem. Rev., 2013, 113, 6659; (b) D. Basavaiah, B. S. Reddy and S. S. Badsara, Chem. Rev., 2010, 110, 5447; (c) D. Basavaiah, K. Venkateswara Rao and R. Jannapu Reddy, Chem. Soc. Rev., 2007, 36, 1581; (d) H. Pellissier, Tetrahedron, 2017, 73, 2831; (e) J. S. Kumar, C. M. Bashian, M. A. Corsello, S. C. Jonnalagadda and V. R. Mereddy, Tetrahedron Lett., 2010, 51, 4482.

8 Deposition Number 2050141 (for $(R)-4 \mathrm{a}$ ) contains the ESI $\dagger$ crystallographic data for this paper.

9 S. Luliński, I. Madura, J. Serwatowski, H. Szatyłowicz and J. Zachara, New J. Chem., 2007, 31, 144.

10 For selected recent reviews, see: (a) Y.-H. Yan, G. Li and G.-B. Li, Med. Res. Rev., 2020, 40, 1558; (b) Y. Xia, K. Cao, Y. Zhou, M. R. K. Alley, F. Rock, M. Mohan, M. Meewan, S. J. Baker, S. Lux, C. Z. Ding, G. Jia, M. Kully and J. J. Plattner, Bioorg. Med. Chem. Lett., 2011, 21, 2533; (c) D. C. McKinney, F. Zhou, C. J. Eyermann, A. D. Ferguson, D. B. Prince, J. Breen, R. A. Giacobbe, S. Lahiri and J. C. Verheijen, ACS Infect. Dis., 2015, 1, 310.

11 N. C. Cohen, J. Med. Chem., 1983, 26, 259.

12 S. C. Mehta, I. M. Furey, O. A. Pemberton, D. M. Boragine, Y. Chen and T. Palzkill, J. Biol. Chem., 2021, 296, 100155.

13 C. A. Smith, N. K. Stewart, M. Toth and S. B. Vakulenko, Antimicrob. Agents Chemother., 2019, 63, e01202. 